\title{
The effect of flanking letters and digits on speed of identifying a letter*
}

\author{
CHARLES W. ERIKSEN \\ University of Illinois, Champaign/Urbana, Ill. 61820 \\ and

\section{ROY M. HAMLIN and CONNIE DAYE} \\ VA Hospital, Danville, Il. 61832
}

\begin{abstract}
Voicing latency for $A$ and $H$ or $U$ and $Q$ was determined when these letters appeared in an exactly known location as a function of whether the letter was flanked by noise letters or digits consisting of curved or angular features. Reaction time was significantly faster when the target letter alone was presented than when flanking noise letters were present. There was no effect attributable to the different kinds of noise (letters vs digits, curved vs angular features). An interpretation in terms of response competition was advanced.
\end{abstract}

In studying the manner in which briefly presented visual displays are processed, Estes and his associates (Estes, 1972; Estes \& Taylor, 1966; Estes \& Wessel, 1966) have investigated, among other variables, the effect of display size or number of noise elements present in the display. When $\mathrm{S}$ is required to search for a given target letter, both errors and response latency increase as the number of noise letters contained in the display increases. Recently, Estes (1972) has analyzed the effect of display size into several components such as retinal position and the possibility of confusions. More recently, Kinchla (in press) has presented a model based solely upon the possibilities of confusions between noise letters and the target.

Both Estes and Kinchla have been concerned with the effect of noise letters on a search task where $S$ is required to locate the target letter. That other contributions of noise letters may also be involved has been indicated by the research of Eriksen and his associates (Eriksen \& Hoffman, 1973; Eriksen \& Hoffman, 1972a, b) on a task where the search component is either minimal or eliminated. These latter investigators have been studying selective attentional or encoding processes in visual displays. Here, circular displays are employed, with a line indicator designating the target letter appearing either simultaneously with the display occurrence or as much as $350 \mathrm{msec}$ before display onset. When the indicator precedes the display by $250-350 \mathrm{msec}$, the search function is eliminated since $S$ has sufficient time to detect and process the indicator before the display occurs. Yet, even under these circumstances, an effect of extraneous letters in the display has been found. Reaction time (RT) in naming the indicated letter increases as the number of irrelevant

*This investigation was supported by U.S. Public Health Service Research Grant MH-1206 and U.S. Public Health Service Research Career Program Award K6-MH-22014. letters in the display increases, with the greatest effect of noise letters occurring when they are within a degree of visual angle of the target letter. As has been found on search tasks (McIntyre, Fox, \& Neale, 1970; Estes, 1972), increasing the dissimilarity between the target and noise elements reduces the interfering effect of the noise (Eriksen \& Hoffman, 1972a).

In the present experiment, the S's task was to voice as rapidly as possible the name of a letter when it appeared $1 / 4$ deg of visual angle above a fixation point in the visual field. The location of this target letter was constant relative to the fixation point, so that there was never any uncertainty on S's part as to where the target letter would appear. In addition to measuring latency when the target letter appeared alone, latency was also determined on trials in which the target letter, when it appeared, was flanked on each side by two other letters or two digits.

Since there is considerable interest in the visual information processing area concerning the possibility of feature analyzing or detecting mechanisms, we also varied the experimental situation in terms of whether the target letter was composed of such "features" as either angles and straight lines or curves. Each type of target was presented with noise letters containing features of either the same or opposite type. If part of the impairment in identifying a letter in the presence of flanking letters is due to the competition for feature analyzing mechanisms, then we might expect that identifying a letter composed of curves from noise letters composed of lines and angles would be more rapid than identifying the letter when it was surrounded by other letters containing curves. The use of digits as noise stimuli was prompted by the consideration that perhaps the cognitively different categories of digits and letters might be relevant to the interfering effect of noise.

\section{METHOD \\ Subjects}

Eight male patients at the Danville VA Hospital served as paid volunteers. They ranged in age from 22 through 61 years. None were on drug medication that would be expected to influence $\mathrm{RT}$, and all were able to achieve a mean voicing latency for single letters of $500 \mathrm{msec}$ or less during a practice session.

\section{Apparatus and Stimuli}

Two fields of a three-channel tachistoscope were used. The adaptation field contained a black $X$ fixation point subtending $.25 \mathrm{deg}$ of visual angle. This field was continuously present except during the 1-sec exposure of the stimulus field. Luminance in both fields was $3.5 \mathrm{~mL}$. The target letter was always presented $.25 \mathrm{deg}$ of visual angle immediately above the fixation point and subtended approximately $.26 \mathrm{deg}$ of visual angle. The stimulus cards were constructed using capital letters from Paratipe No. 11316 pressure lettering. The angle target 
Table 1

Mean RTs in Milliseconds for the Two Pairs of Target Letters Under the Different Noise Conditions

\begin{tabular}{lccccc}
\hline & \multicolumn{5}{c}{ Noise Conditions } \\
\cline { 2 - 6 } $\begin{array}{l}\text { Target } \\
\text { Letters }\end{array}$ & $\begin{array}{l}\text { Target } \\
\text { Alone }\end{array}$ & $\begin{array}{c}\text { Angle } \\
\text { Letters }\end{array}$ & $\begin{array}{c}\text { Curved } \\
\text { Letters }\end{array}$ & $\begin{array}{c}\text { Angle } \\
\text { Digits }\end{array}$ & $\begin{array}{c}\text { Curved } \\
\text { Digits }\end{array}$ \\
\hline A and H & 297 & 315 & 317 & 319 & 315 \\
U and Q & 360 & 379 & 376 & 380 & 375 \\
\hline
\end{tabular}

letters were $\mathrm{A}$ and $\mathrm{H}$, and the curved letters, $\mathrm{U}$ and $\mathrm{Q}$. One set of stimulus cards contained only a single letter, A or $\mathrm{H}$, or $\mathrm{U}$ or $\mathrm{Q}$. In the conditions in which noise letters or digits were present, they flanked the target letter on each side, and the spacing was such that the nearest contours of adjacent letters were separated by $.5 \mathrm{deg}$ of visual angle. The angle noise letters were $\mathrm{M}$ and $\mathrm{F}$, and the curved ones, $J$ and $G$. The corresponding curved and angle digits were 3 and 6 , and 4 and 7 . An example of an angle target letter with curved digit noise would be $36 \mathrm{~A} 36$, and of a curved target letter with angle letter noise, MFUMF. Initiation of the display simultaneously activated a Lafayette digital timer, and S's response activated a Scientific Prototype Model 761-G voice key, which stopped the timer. RT was measured to the nearest millisecond.

\section{Procedure}

Each $\mathrm{S}$ served in one practice and four experimental sessions. For each experimental session, only one pair of letters was used (angles or curves), and S was told which pair of letters would be presented during that session. Before each session began, 15 practice trials were administered. S was asked to look at the fixation point on the screen and then was orally warned "ready" when a trial was about to begin. Initiation of a display presentation was by the E. S was instructed to say the target letter as rapidly as possible, and was also instructed that in those blocks of trials where noise letters were present, he was to ignore them. He was further informed that the target letter would always appear immediately above the fixation point. During each session, five blocks of 24 trials each were administered. During one of these blocks of trials, only a single letter occurred on the stimulus card. In the remaining four blocks, the target letter was flanked by either curved digits, 3 and 6 , angle digits, 4 and 7 , curved letters, $J$ and $G$, or angle letters, $M$ and $F$. Over the experimental sessions, $S$ had a total of 48 trials in each of the 10 experimental conditions. Order of presentation of the 10 experimental conditions was counterbalanced across Ss and sessions as closely as possible.

\section{RESULTS}

In Table 1, mean RT is shown for angle and curved target letters for the conditions in which the letter appeared alone and when it appeared with the varying kinds of noise stimuli. A three-way analysis of variance (Ss, curved vs angle target letters, and kind of noise) yielded significant effects $(p<.001)$ for Ss, angle vs curved letters, and kind of noise stimuli. None of the interactions at tained significance $(\mathrm{p}>.10)$.

As can be seen from Table 1, RT to the letters $U$ and $\mathrm{Q}$ was longer than it was to $\mathrm{A}$ and $\mathrm{H}$ under all noise conditions. But the major concern is the effect of the noise conditions. Both $\mathrm{A}$ and $\mathrm{H}$, and $\mathrm{U}$ and $\mathrm{Q}$ have significantly faster RTs when the letter occurs alone than when flanked by noise stimuli. There appears to be no differential effect of the different types of noise. Not only is there no appreciable difference in voicing latency as a function of whether the target letter is flanked by other letters or by digits, but target letters consisting of angles and straight lines are not impaired any more when flanked by letters or digits consisting of angles and straight lines than when flanked by stimuli containing curves. The converse also holds.

\section{DISCUSSION}

Intuitively, it seems reasonable that, when $S$ must search a display, the latency for response to a target should increase with the number of noise items presented in the display. After all, some level of processing would be required to locate the target among the noise. But in the present experiment, where the target location is well defined and known to $S$ beforehand, the impairment in target identification obtained when noise elements are present would indicate that noise is exerting an influence over and above that associated with a scanning or search task. Eriksen \& Hoffman (1973) have suggested that the visual attentional field has a focus of about $1 \mathrm{deg}$ of visual angle in which all stimuli are simultaneously or parallel processed. They have further shown that the interference produced by noise elements occurs primarily at the response level as distinguished from input processing. They found, for example, that if the noise elements and the target letter both lead to the same lever-movement response, little or no effect of noise or RT is obtained.

The present results are consistent with the above explanation. Here the impairment in RT produced by the noise letters would be due to the simultaneous processing of both the noise and target with resulting response competition. In other words, the interference does not appear to be on the input side due to competition for common feature analyzers. Instead, the noise and target are processed in parallel, but the response channel is serial. Only one letter can be voiced at a time. With both a letter and two digits or two or more different letters available from the processing system to the response system, an additional time element is involved in the RT, reflecting a selection of the correct response from the several possible responses available. This additional selection time is represented by the increase in RTs obtained in the noise conditions over those of the single-letter condition.

Even if the results are ascribed to response competition, the lack of differences in the amount of interference contributed by noise varying on such dimensions as angles, straight lines, curves, and conceptual classes cannot be interpreted as indicating the lack of validity of processing mechanisms that are sensitive to these types of categorizations. Whether subprocessing units sensitive to these kinds of categorizations exist or not is still a moot point.

Similarly, the difference in RT for A and $\mathrm{H}$ as opposed to $\mathrm{U}$ and $Q$ does not seem to be attributable to a difference in input processing for these different letters. A replication experiment was performed in which, instead of vocalizing the target letter, $S$ was required to move a lever one direction for an $A(U)$ and in the other direction for a. $H(Q)$. The elimination of the voicing also eliminated the difference in RT between these two sets of letters. Thus, it would appear that the difference in RT obtained in the present experiment reflects a difference in facility with which the response $A$ and $H$ can be initiated relative to $U$ and $Q$ or perhaps to a diffential sensitivity of the voice key to frequencies involved in the different sounds.

\section{REFERENCES}

Eriksen, C. W., \& Hoffman, J. E. Temporal and spatial characteristics of selective encoding from visual displays. Perception \& Psychophysics, 1972a, 12, 201-204.

Eriksen, C. W., \& Hoffman, J. E. Some characteristics of selective attention in visual perception determined by vocal reaction time. Perception \& Psychophysics, 1972b, 11, 169-171. 
Eriksen, C. W., \& Hoffman, J. E. The extent of processing of noise elements during selective encoding from visual displays. Perception \& Psychophysics, 1973, 14, 155-160.

Estes, W. K. Interactions of signal and background variables in visual processing. Perception \& Psychophysics, 1972, 12, 278-286

Estes, W. K., \& Taylor, H. A. Visual detection in relation to display size and redundancy of critical elements. Perception \& Psychophysics, 1966, 1, 9-16.

Estes, W. K., \& Wessel, D. L. Reaction time in relation to display size and correctness of response in forced-choice visual signal detection. Perception \& Psychophysics, 1966, 1, 369-373.

Kinchla, R. Detecting target elements in multi-element arrays: A confusability model. Perception \& Psychophysics, in press.

McIntyre, C., Fox, R., \& Neale, J. Effects of noise similarity and redundancy on the information processed from brief visual displays. Perception \& Psychophysics, 1970, 7, 328-332.

(Received for publication September 10, 1973.)

\section{A note on the negative automaintenance procedure*}

\section{ROBERT W. GRIFFIN and MICHAEL E. RASHOTTE Florida State University, Tallahassee, Fla. 32306}

Some experiments have reported that illumination of a response key prior to grain presentation to hungry pigeons establishes high levels of pecking on the lighted key despite a negative correlation between pecks and presentation of grain. Initial attempts to employ this "negative automaintenance" procedure resulted in very low levels of pecking, but pecking developed and was maintained at a high level in all pigeons when the chamber illumination, the trial length, and the intertrial interval were adjusted.

When a negative automaintenance procedure is employed with pigeons, grain presentation following brief illumination of a response key is cancelled by a single peck on the lighted key. Despite the negative correlation between keypecking and grain presentation, pigeons readily develop and maintain pecking on the lighted key in some experiments (e.g., Schwartz, 1972; Schwartz \& Williams, 1972; Williams \& Williams, 1969), but not others (Brownstein, personal communication; Granat, 1972; Hursh, Navarick, \& Fantino, in press; Passe, 1972). These findings indicate that a negative correlation between keypecks and grain presentation is not a sufficient condition for the maintenance of keypecking on the negative automaintenance procedure.

This laboratory has experienced considerable difficulty in maintaining keypecking in pigeons with the negative automaintenance procedure, and the present note reports our solution to this difficulty. A number of sources (Groves \& Brownstein, 1973; Wasserman, 1972) and personal communications ${ }^{1}$ suggested that the level of illumination in the experimental chamber and the relative durations of intertrial and trial periods might be important in obtaining high keypeck levels. Specifically, it seemed that a high level of chamber illumination in conjunction with standard key illumination, and a long intertrial interval in conjunction with a short trial duration, might yield strong keypecking. In our earlier

*This research was supported in part by Grant GB-28224 from the National Science Foundation to Florida State University (M.E.R., principal investigator). Reprints may be obtained from either author at Department of Psychology. Florida State University, Tallahassee, Fla. 32306 . unsuccessful work, the chamber was illuminated by a $25-\mathrm{W}$ bulb run at $65 \mathrm{~V}$ ac, the trial duration was $9 \mathrm{sec}$, and the intertrial interval was initially $60 \mathrm{sec}$ on the average and later was changed to $30 \mathrm{sec}$ on the average. The present paper reports high levels of keypecking in all four pigeons trained in a negative automaintenance procedure with chamber illumination and intertrial/trial durations set at "best guess" values based on available evidence. The chamber was illuminated by a $25-\mathrm{W}$ frosted bulb run at $115 \mathrm{~V}$ ac, and the intertrial and trial durations were 120 and $6 \mathrm{sec}$, respectively. Finally, in our earlier procedures, a trial was terminated by a single peck (i.e., the keylight was extinguished and food was not presented), whereas in the present work the trial duration was fixed.

\section{METHOD}

Subjects

Four experimentally naive male white Carneaux pigeons were maintained at $80 \%$ of their free-feeding weights. They were individually housed in wire mesh cages under a 24-h light-dark cycle (14 h light, $10 \mathrm{~h}$ dark). Water and grit were continuously available in the home cages.

\section{Apparatus}

Two Foringer Model 1104 test chambers $(40$ × 37.5 x $39.4 \mathrm{~cm}$ i.d.) were painted flat black and were housed in wooden boxes. A clear-plastic response key and an in-line IEE projector were mounted behind a $2.54-\mathrm{cm}$-diam hole $25.4 \mathrm{~cm}$ above the floor and $6.4 \mathrm{~cm}$ to the left of the center on one wall. Another response key on the same wall was covered. A minimum force of $28 \mathrm{~g}$ closed the switch on the response key. Grain was presented in a $5.1 \times 5.7 \mathrm{~cm}$ opening centered on the same wall, with the bottom edge of the opening $10.2 \mathrm{~cm}$ above the floor. Constant visual monitoring of each chamber was provided by television cameras mounted over an opening $(38.1 \mathrm{~cm} \mathrm{sq})$ in the ceiling of each box enclosing the test chambers. The opening was covered with chicken wire, and the area between the opening and the camera lens was enclosed by black cardboard. The chamber was illuminated by a $25-\mathrm{W}$ frosted incandescent bulb, housed in a white enclosure fronted with sandblasted Plexiglas and operated at $115 \mathrm{~V}$ ac (photometric readings obtained $0.07 \mathrm{fc}$ ). The light enclosure was mounted flush with the ceiling surface in the rear corner of the opening diagonal to the response key. White noise was delivered through a 4-in. speaker located behind the front wall. An exhaust fan provided ventilation. Total masking noise measured $78 \mathrm{~dB}$ SPL from the center of the chamber. Television monitors and electromechanical control and recording equipment were located in an adjoining room. 